\title{
A Escola em Diáspora
}

\author{
School in Diaspora
}

\author{
Anderson Rodrigues Corrêa \\ Universidade Federal do Rio Grande do Sul \\ arocorrea@gmail.com
}

\section{Letícia Fonseca Richthofen de Freitas}

Universidade Federal de Pelotas

leti.freitas@terra.com.br

\section{Resumo}

O trabalho analisa o filme francês: 'Entre les Murs' Entre os Muros da Escola. A investigação permeará as narrativas presentes na película, nas quais são abordadas questões de identidade, sexualidade, gênero, discriminação, preconceito, enfim, são problematizadas as distintas relações retratadas naquele ambiente escolar. A análise está conduzida pelo viés dos Estudos Culturais, no qual as problematizações dos enunciados e das práticas culturais ultrapassam o âmbito escolar e interagem com a construção de diversas narrativas, distintos textos e linguagens, nos múltiplos espaços vivenciados pelos sujeitos.

Palavras - Chave: Narrativas; escola; identidades; pedagogias culturais

\begin{abstract}
This paper is an evaluation of French film 'Entre les Murs', directed by Laurent Cantet. The film evaluation considers the narratives that occur along the film about identity, sexuality, discrimination, prejudices, and others, that problematize the different relationships that appear inside the school environment. This evaluation is conducted under the point of view of Cultural Studies, considering that the problematization of the statements and of the cultural practices that occur inside the school environment exceed its limits and interact with the development of the different narratives, texts and languages inside the different areas experienced by the subjects.
\end{abstract}

Keywords: Narratives; school; identity; pedagogy; cultural studies 


\section{O Filme...}

O presente artigo objetiva efetuar uma análise do filme: 'Entre os Muros da Escola', baseado em um livro homônimo de François Bégaudeau, dirigido por Laurent Cantet e ganhador do prêmio Palma de Ouro do Festival de Cannes de 2008. No livro, o educador relata sua trajetória como professor de francês de uma escola de ensino médio, situada na periferia de Paris, local de mistura étnica e social, um microcosmo da França contemporânea. Já o filme, no qual François Bégaudeau interpreta a si mesmo, busca desvendar o cotidiano de uma escola na França contemporânea.

O campo teórico que embasa este trabalho é o dos Estudos Culturais, no seu cruzamento com a Educação e a Pedagogia, o qual considera central o papel da linguagem como constituidora de todos os aspectos da vida social. Os Estudos Culturais em Educação ressignificam o campo pedagógico e "questões como cultura, identidade, discurso e política de representação passam a ocupar, de forma articulada, o primeiro plano da cena pedagógica" (COSTA, 2005, p. 112).

Dessa forma, o foco de análise deste artigo é justamente a questão das identidades, mais especificamente as assim chamadas identidades em diáspora e as identidades de gênero, as quais são, dentre outros temas, abordadas no filme.

Isso posto, considera-se, em primeiro lugar, a importância de se analisar filmes no espaço acadêmico, no sentido de investigar as narrativas fílmicas como produtoras dos mais diversos significados culturais e sociais. Conforme afirma FANTIN (2009, p. 221): os filmes atuam "no âmbito da consciência do sujeito e no âmbito sociopolítico cultural, configurando-se num formidável instrumento de intervenção, de pesquisa, de comunicação e de educação, e num espaço de mediação entre o visível e o invisível" (Fantin, 2009, p. 221).

Apesar de, como sublinha a autora, os filmes atuarem de maneira bastante ampla, interessa-nos, aqui, levar em conta o papel 'educativo' dos filmes, analisando de que maneira os discursos e as narrativas que neles circulam produzem significados e ensinam lições a partir desses significados produzidos. Com base nessas considerações, parte-se do princípio de que a Educação, no seu sentido mais amplo, acontece não somente no âmbito da escola, mas nas mais diversas instâncias sociais e nos mais variados espaços do mundo contemporâneo. Nesse sentido, Costa (2005, p. 116) ressalta o fato de também sermos educados "por imagens, filmes, textos escritos, propagandas, charges, jornais e televisão, seja onde for que estes artefatos se exponham".
É necessário ressaltar ainda que, neste artigo, os filmes são entendidos como artefatos culturais, instâncias pedagógicas nas quais circulam múltiplas pedagogias culturais, que colaboram na constituição histórica dos sujeitos, nas mais diversificadas culturas. Ainda de acordo com Costa (2000, p. 206-207), "estamos inapelavelmente imersos em culturas cujos discursos e práticas nos instituem como sujeitos históricos que somos, interessa-nos procurar compreender os processos que nos constituem e nos quais nos constituímos". Sendo assim, a análise de certas pedagogias culturais presentes em narrativas fílmicas ajudam a entendermos como se dão alguns desses processos que nos constituem e nos quais nos constituímos.

Com tal espírito investigativo serão explorados alguns diálogos do filme: 'Entre os Muros da Escola'. É interessante destacar que o filme se utiliza de técnicas de documentário e os personagens são os próprios atores na vida real. A temática central do filme gira em torno das aulas de francês ministradas pelo professor François Marin em uma turma de oitavo ano. A película também amplia o olhar do espectador para as relações cotidianas entre os diversos atores presentes em um ambiente escolar: alunos, professores, direção, enfim, a comunidade escolar como um todo.

O ambiente escolar retratado no filme é tenso e permeado por conflitos; a sala de aula do professor Marin esquadrinha todo tipo de complexidade existente na sociedade contemporânea, um mundo onde a instabilidade e a luta pela produção de sentidos prevalecem. Nesse sentido, Costa (2009), ao analisar algumas das alterações sofridas pelas distintas sociedades contemporâneas, as quais também afetam as relações educacionais - refletidas e exploradas no filme 'Entre os Muros da Escola', sublinha que:

a vida nas sociedades contemporâneas tornou-se complexa, confusa, fragmentária e difícil de administrar. Os humanos destes tempos precisam moldar suas estratégias de existências em meio a um conjunto labiríntico de condições e possibilidades instáveis, provisórias, mutantes (p.15).

O filme se passa em uma Paris atual, difusa, ampla, cosmopolita; metrópole onde convivem, não tão pacificamente, milhares de pessoas, das mais distintas etnias, coabitando um espaço em uma sociedade extremamente complexa e, de certa maneira, bastante fragmentada. Neste panorama, apresenta-se o desenrolar do cotidiano escolar do professor François Marin, seus encantos, desencantos, tentativas, buscas, 
lutas, conquistas, vitórias, crises - o cotidiano de uma sala de aula repleta de adolescentes das mais distintas etnias.

Bégaudeau assumiu muito bem o papel de professor, mas são os adolescentes que impressionam: os intérpretes de Esmeralda, Khoumba, Boubacar e Souleymane têm, cada um, momentos solo surpreendentes. François Marin e seus colegas professores preparam o novo ano letivo em uma difícil escola da periferia parisiense. Munidos das melhores intenções, eles se apoiam mutuamente para manter vivo o estímulo de dar a melhor educação a seus alunos. A sala de aula testemunha os choques entre as diferentes culturas e por mais inspiradores e divertidos que sejam os adolescentes, seu difícil comportamento pode acabar com qualquer entusiasmo dos professores.

\section{Entre os Muros...}

Conforme já foi explicitado anteriormente, as análises se debruçam sobre a questão das identidades. Segundo Arfuch (2002), a questão da identidade, ou melhor, das identidades, no plural, tem ocupado, na última década, um lugar central nos mais diversos domínios acadêmicos. Moreira (2005) ressalta a crescente complexidade das diversas esferas da vida social - nacional, religiosa, étnica, linguística, regional, local, de gênero - nas quais as identidades são produzidas, confirmadas e/ou contestadas. Dessa forma, "não causa espanto que a identidade se tenha imposto como categoria de particular relevância para a compreensão dos fatos sociais contemporâneos" (p. 126).

Um dos aspectos mais relevantes quando se estudam os processos de constituição identitária na contemporaneidade diz respeito às assim chamadas identidades em diáspora. Com o advento de um mundo globalizado, os fluxos migratórios cada vez maiores "estão mudando de composição, diversificando as culturas e pluralizando as identidades culturais dos antigos Estados-nação dominantes, das antigas potências imperiais, e, de fato, do próprio globo" (HALL, 2003a, p. 45).

Essas mudanças se fazem presentes na sala de aula do filme, repleta de imigrantes ou de seus filhos. São recorrentes, na película, os momentos de conflito e de negociação em relação às identidades dos alunos e do professor: os alunos contestando aquilo que o professor simboliza: o francês e sua identidade colonial. Tais embates se dão das mais diversas maneiras, como no momento em que Marin utiliza como exemplo, na construção de uma frase, o nome Bill. Esse acontecimento acarreta uma conturbada discussão sobre a escolha do nome, do por que ser utilizado um nome desconhecido e não usual para a maioria dos alunos presentes. Nome que seria muito 'esquisito' para aquele grupo de alunos, conforme explicitado no excerto de um diálogo do filme:

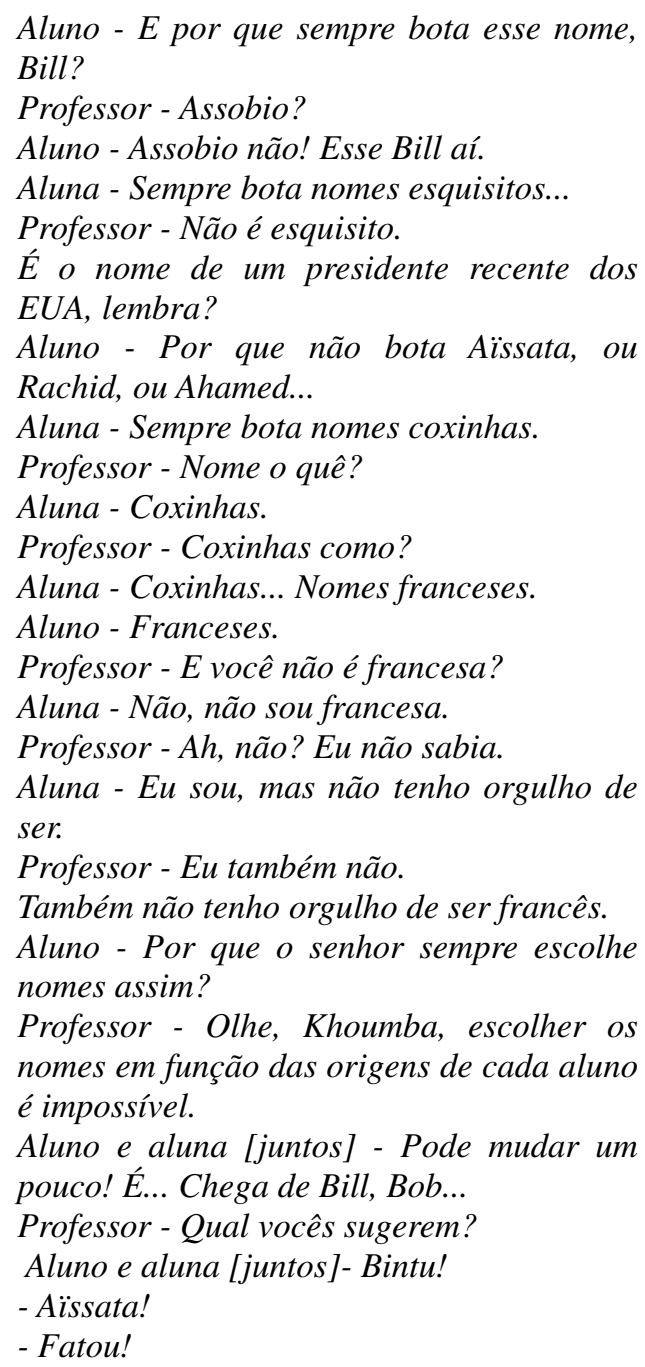

A sala de aula está repleta de alunos cujas famílias possuem múltiplas origens étnicas; por isso, a escolha do nome Bill, considerado um nome 'coxinha', gera uma discussão em tom bastante desafiador, com deboche e ironia permeando o diálogo. Para os alunos que se posicionam, o nome utilizado pelo professor não faz parte do seu universo; eles sugerem outros nomes, que lhes seriam mais familiares - Bintu, Aïssata, Fatou -, uma vez que o professor, segundo os alunos, só escolhe nomes franceses, 'coxinhas'. Percebe-se que Marin questiona se o aluno também não seria francês, o que de certa maneira desestabiliza o aluno, que concorda, mas que diz não ter orgulho de 
o ser.

Esse pequeno excerto retrata o que Hall (2003a) denomina de a 'experiência da diáspora', ou seja, uma experiência que de certa maneira constitui a identidade de pessoas que pertencem a dois ou mais territórios, a duas ou mais 'comunidades imaginadas' no sentido atribuído por Anderson. Freitas (2006), em seu estudo sobre gaúchos que migraram do Rio Grande do Sul para Mato Grosso, ressalta o fato de muitos deles, apesar de continuarem cultuando as tradições gaúchas, também reconhecem pertencer, de certa maneira, ao novo território. Nesse sentido, Haesbaert postula que na contemporaneidade o mundo pode ser entendido como o 'mundo das múltiplas territorialidades' (1997), uma vez que "as identidades territoriais nos moldes mais tradicionais não estão desaparecendo, mas se reformulando" (1999, p. 185). No caso dos alunos retratados no filme, a maioria nascida na França e filhos de imigrantes ou eles próprios imigrantes, suas identidades se constituem a partir de múltiplos pertencimentos, inclusive territoriais: "na situação da diáspora, as identidades se tornam múltiplas" (HALL, 2003b, p. 27) ${ }^{1}$.

A partir do episódio da escolha do nome Bill, busca-se problematizar a questão das identidades culturais, destacando a importância que as discussões sobre as identidades assumem nas teorias sociais contemporâneas. Ainda de acordo com Hall, "as velhas identidades, que por tanto tempo estabilizaram o mundo social, estão em declínio, fazendo surgir novas identidades e fragmentando o indivíduo moderno, até aqui visto como um sujeito unificado" (2002, p. 07). O autor continua sua argumentação apontando para a 'crise de identidade, que para ele:

é vista como parte de um processo mais amplo, de mudança, que está deslocando as estruturas e processos centrais das sociedades modernas e abalando os quadros de referência que davam aos indivíduos uma ancoragem estável no mundo social (p. 07).

Um dos aspectos que davam essa sensação de ancoragem, de pertencimento a um grupo, eram as comunidades (BAUMAN, 2003). Pertencer a uma comunidade, seja ela uma nação, uma região ou um grupo étnico, territorialmente delimitado, parece ser cada vez menos comum em um mundo de intensos fluxos migratórios - sejam eles livres ou impostos por motivos políticos e/ou econômicos.

No trecho destacado, a seguir, novamente a questão do conflito de identidades se impõe. No caso abaixo, um aluno relata o preconceito sofrido por ser diferente, por usar roupas diferentes e, sobretudo, por provavelmente ter sido identificado como sendo de origem árabe:

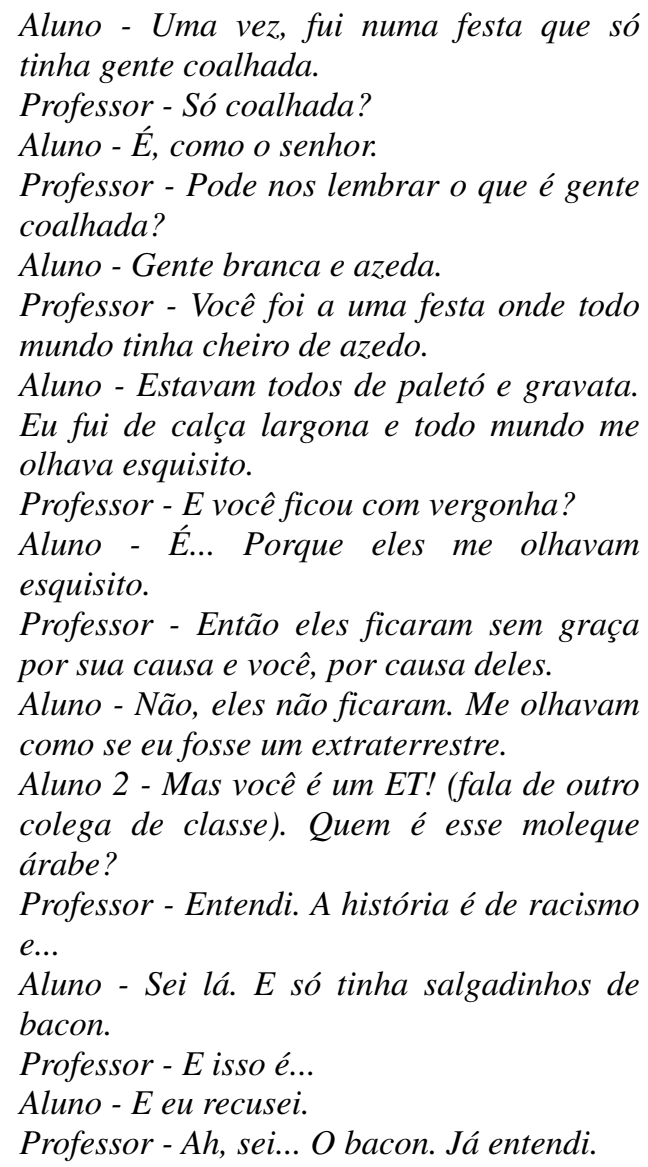

No trecho acima o aluno, ao relatar sua experiência em um festa em que se sentiu deslocado por ser de origem árabe, por se vestir de forma diferente, também se posiciona de maneira a contestar os padrões daqueles que o discriminaram - no caso os franceses chamando-os de gente 'coalhada' - branca e azeda. O professor, também alguém 'coalhada', tenta brincar com o aluno perguntando se as pessoas tinham cheiro de azedo, mas ele, aluno, descreve a maneira como os presentes se vestiam e como o olharam por estar com roupas diferentes, inapropriadas.

A intervenção do professor se dá então no sentido de tentar mediar a situação, perguntando ao aluno se todos ficaram constrangidos por causa das roupas que usavam; a resposta revela que não, que somente o rapaz de origem árabe se sentiu constrangido, o que, segundo outro aluno, seria uma demonstração de racismo.

Segundo Bauman (2005), nesse terreno fluido e móvel em que se movimentam as identidades, há constantes lutas, mas há aqueles que têm menos 
chance de reivindicar e de legitimar suas identidades. De acordo com o autor, há um espaço abjeto no qual se situam "as pessoas que têm negado o direito de reivindicar uma identidade 'distinta' da classificação atribuída e imposta" (p. 45), e nesse espaço parece estar o aluno acima, uma vez que sua origem árabe já o coloca em uma posição estereotipada frente aos franceses. Tal espaço não possui fronteiras físicas, mas fronteiras sociais e culturais que barram o acesso aos diferentes, aos outros, àqueles que não se enquadram no caso específico do filme, toda sorte de refugiados e migrantes.

Ainda em relação aos conflitos gerados pela presença de imigrantes em países como a França e em outros países europeus, Bauman destaca:

Em 1994, um cartaz espalhado pelas ruas de Berlim ridicularizava a lealdade a estruturas que não eram mais capazes de conter as realidades do mundo: "Seu Cristo é judeu. Seu carro é japonês. Sua pizza é italiana. Sua democracia, grega. Seu café, brasileiro. Seu feriado, turco. Seus algarismos, arábicos. Suas letras, latinas. Só o seu vizinho é estrangeiro" (2005, p. 32).

O texto do cartaz, referido por Bauman, nos alerta para as distintas posições que podem ser assumidas pelos sujeitos nessa atual condição em que vivemos. Retrata, inteligentemente, como estamos nos constituindo sujeitos na contemporaneidade: somos produzidos por múltiplas identificações, inúmeros produtos, constantes alterações de valores. Movidos e regidos por uma ética e estética consumista, descartável, vivemos em uma constante mutação entre identidades. A condição diaspórica, vivida por muitos dos personagens do filme é uma delas.

Outro conflito retratado no filme em relação a essa questão das identidades em diáspora acontece por causa dos usos da língua; a discussão é sobre a utilização da norma padrão da língua francesa considerada correta na sociedade francesa letrada, e artificial para os alunos. Abaixo foi transcrita uma parte do diálogo em que tal choque linguístico é abordado:

Aluno - Ninguém, fala assim. É sério!

Aluno - Eu tinha razão, era 'fusse'.

Professor - Será que posso responder a pergunta que me fizeram?

Se estiverem interessados mesmo.

Aluno - Eu autorizo.

Professor - Percebo que antes mesmo de aprender o uso do imperfeito do subjuntivo, já estão me dizendo que ele não serve para nada. Primeiro, aprendam. Depois, vocês podem questionar o uso dele.

Aluno - Por que está criticando a gente?

Aluno - Eles têm razão. A linguagem que a gente usa é diferente. Essa é antiga.

Nem minha avó fala assim.

Aluno - Nem meu bisavô falava!

Aluno - Isso é coisa da Idade Média.

Professor - Não é da Idade Média.

Aluno - É coisa de burguês!

Aluno - Quando foi a última vez que ouviu alguém falando assim?

Professor - Ontem. Conversando com meus amigos. É que o problema...

Aluno - Uma pessoa normal! Gente normal não fala assim! Nas ruas, ninguém fala assim.

Professor - Posso responder? Eu gosto de discutir, mas com calma. É claro que é verdade que nem todos falam assim. É raro alguém que fale. Eu diria que só os esnobes usam o imperfeito do subjuntivo.

Aluno - E o que é esnobe?

Professor - Esnobes são pessoas um pouco, um pouco afetadas, rebuscadas, que falam com maneirismos...

Aluno - Os homossexuais?

Professor - Não, não são os homossexuais. A pessoa pode ser afetada e refinada sem ser homossexual, Boubacar. Em todo caso podemos achar que esse registro mais afetado seja uma coisa de burguês. $O$ importante é avaliar os registros que existem, como sempre digo e vou repetindo $e$ saber alternar todos: o coloquial, o formal, o oral e a escrita e viajar entre eles para dominar todos.

Aluno - Como sabemos o que usamos para escrever e para falar?

Aluno - Como saber se a palavra fica melhor na linguagem oral ou na escrita?

Professor - Bom, isso é uma coisa que normalmente se aprende com a prática. Quer dizer. É preciso ter um pouco de intuição.

A discussão reproduzida ocorreu durante uma aula sobre a utilização correta de tempos verbais, segundo a norma padrão, caracterizando-se por um momento de desafio que os alunos promovem. O professor Martin conduziu a discussão de forma bastante esclarecedora, apontando para as distintas formas e utilizações da língua: 'a coloquial, a formal, a oral e a escrita.' Martin 
alertou para o cuidado que se deve ter com os padrões linguísticos, os próprios estilos e locais de aplicação. Para os alunos, entretanto, a norma culta/padrão seria a língua utilizada pelo colonizador, língua que eles não dominam e contra a qual tentam se rebelar, numa clara demonstração de resistência e de protesto. No diálogo transcrito acima, o uso da língua padrão, segundo o aluno, se restringiria somente a sujeitos esnobes, afetados, homossexuais. A disputa estava lançada: Como falar correto? Quem fala corretamente? Qual a verdadeira necessidade? Para quê? Para quem? Onde? Quando?

As perguntas estavam geradas e os jogos do poder presentes em cada argumento defendido pelos alunos e pelo professor. A discussão foi bastante profícua e problematiza o choque cultural enfrentado e reproduzido no espaço de poder refletido pela adequação do tipo de linguajar utilizado em cada cultura, espaço e tempo; enfim, nossas próprias vivências culturais, refletidas na forma que usamos nossa língua no cotidiano.

De fato, no que se refere à questão da linguagem e da utilização da língua, temos um campo no qual se processam sérios embates, uma vez que, a partir de uma visão etnocêntrica, nossa língua, nossa maneira de falar, de se expressar, nossa variedade linguística tende a ser sempre a 'correta', em detrimento da maneira de falar e de se expressar dos outros, da sua variedade linguística. Em relação a tal constatação, Silveira (2009), observa que:

Quando falamos sobre vivências culturais, a primeira tendência é tornar as nossas como "corretas", "adequadas", "naturais" e "normais", enquanto as dos outros - os que não pertencem ao nosso grupo consideramos "exóticas", "inadequadas", "espantosas" ou, decididamente, "risíveis". Essa tendência moralista e etnocêntrica parece se exacerbar quando falamos da nossa língua - da variedade linguística que usamos para falar e, secundariamente, para escrever - em relação às variedades de outros usuários (SILVEIRA, 2009, p. 192).

No filme o professor Martin alertou seus alunos para o cuidado que eles deveriam ter aos padrões linguísticos, à variedade linguística, aos próprios estilos e aos locais de aplicação, mas a questão era bem mais profunda do que somente a utilização do tempo verbal correto: o embate se travava mais pela legitimidade de um registro linguístico desprestigiado, utilizado por imigrantes e por camadas menos favorecidas da população, frente a outro registro cujo poder simbólico como sendo a maneira 'correta' de se utilizar a língua é inegável.

\section{É? Ou não É?}

Nesta seção, cabe retomar parte do diálogo transcrito anteriormente, no qual os alunos associam a utilização de uma linguagem formal, culta, aos homossexuais. Praticamente durante todo o filme, as questões de gênero, são fortemente registradas. Em uma das falas alguns alunos questionam a sexualidade do professor Martin:

Professor - Quer fazer alguma pergunta? Então pergunte.

Aluno - Não, é muito sacana. Não é nada... Vai pegar mal pro senhor.

Professor - Pergunte e pronto. Ande!

Aluno - Dá sua palavra?

Professor - Ande logo!

Aluno - Sei lá... O pessoal diz... Não fui eu que disse! Ouvi dizer que o senhor gosta de homem.

[Turma toda ri e debocha do professor] Aluno - Não fui eu que disse.

Professor - Quem disse isso?

Aluno - As pessoas. Elas falam: O Sr. Marin gosta de homem.

Professor - Certo. São os outros que dizem, você não? Isso não te interessa.

Aluno - Eu não ligo.

Professor - Então por que me perguntou?

Aluno - Por causa dos outros. Sou portavoz.

Professor - Esse assunto não te interessa. Aluno - Se gosta de homem, tudo bem. Professor - É isso aí.

Aluno - Mas é verdade ou não?

Professor - Mesmo assim quer saber? Aluno - Não é insulto ser homossexual. Professor - Você diz que não é insulto, mas tenho a impressão que não acha legal. Parece que não aceita homens gostarem de homens.

Aluno - Pode ser, não sei. Mas é verdade ou não?

Professor - Não, não é verdade. Está mais tranquilo? Está?

Aluno - Na boa

Professor - Na boa nada. Desculpe decepcionar você.

A discussão entre o professor Marin e seus alunos foge do conteúdo proposto pela disciplina e entra para 
um campo da própria identidade do professor. Os alunos, de forma irônica e até mesmo agressiva, questionam se o professor é realmente homossexual. É oportuno trazer as contribuições de Louro (2001) em relação às identidades de gênero, nas quais a autora destaca que as identidades não são tão fixas e estáveis quanto parecem:

Ao conceber a identidade heterossexual como normal e "natural", nega-se que toda e qualquer identidade (sexual, étnica, de classe ou de gênero) seja uma construção social, que toda identidade esteja sempre em processo, portanto nunca acabada, pronta ou fixa. Pretende-se que as identidades sejam em algum momento mágico - congeladas (p. 139).

Outro ponto importante de ser debatido sobre as questões de gênero diz respeito ao caráter social e cultural das identidades, construído e catalisado através de distintos espaços e tempos históricos em contraposição a uma visão biologizante do gênero. Meyer (2001) sugere que "nós aprendemos a ser homens e mulheres desde o momento em que nascemos, até o dia em que morremos e essas aprendizagens se processam em diversas instituições sociais, a começar pela família, passando pela escola, pela mídia, pelo grupo de amigos, pelo trabalho, etc.”. Quanto ao gênero, a autora sustenta a ideia de que "gênero reforça a necessidade de se pensar que há muitas formas de sermos mulheres e homens, ao longo do tempo, ou mesmo tempo histórico, nos diferentes grupos ou segmentos sociais" (MEYER, 2001, p. 32).

Esse também é um campo contestado de significações, no qual muitos discurso se contrapõem a fim de adquirir legitimidade. De certa forma, a desconfiança pelo fato de o professor ser homossexual gerou curiosidade e até um preconceito velado, não assumido por parte dos alunos. Como aponta Corrêa (2007, p. 97), "o conceito de gênero possibilita um olhar plural, diversificado sobre distintas construções de masculinidade e de feminilidade". Complementando a argumentação, o autor sugere que "olhar com essa lente amplia as discussões para além de lógicas binárias, hermeticamente estagnadas. O singular é substituído gradativamente pelo plural, sugerem-se: identidades, masculinidades, feminilidades, homossexualidades, sujeitos e comportamentos variados" (idem).

\section{As Luzes se Acendem...}

O que podemos afirmar, após as análises aqui empreendidas, é que elas são provisórias e que não pretendem dar conta do todo. Partindo-se do princípio de que identidades são um campo contestados de significação, no qual se travam constantemente lutas e batalhas, as análises realizadas aqui tiveram como objetivo situar os sujeitos - histórica e culturalmente no sentido de problematizar todos esses embates na busca pela produção de sentidos identitários.

No caso particular dessa análise, privilegiaram-se as identidades em diáspora e as identidades de gênero, mas cabe lembrar que todo o campo identitário está permeado por tensões. De acordo com Bauman (2005, p. 83), a identidade é um "conceito altamente contestado. Sempre que se ouvir essa palavra, pode-se estar certo de que está havendo uma batalha. O campo de batalha é o lar natural da identidade".

Com base na ideia de que não houve a pretensão de esgotar as discussões suscitadas pelo filme, sublinhamos a necessidade de que outras narrativas e histórias do viver 'Entre os Muros da Escola' sejam contadas. Como sugere Win Wenders: 'As histórias não desaparecerão. Assim como, a necessidade de ouvir e ver histórias!' Por fim, compreende-se as análises aqui realizadas como uma pequena história, uma mostra, uma ínfima fração do todo. Deixamos apenas mais questionamentos, jamais certezas, comprometidos em analisar por outros ângulos as narrativas produzidas e reproduzidas no filme 'Entre os Muros da Escola' e colocar em xeque modelos legitimados e compreendidos como naturais.

1 É importante ressaltar que adotamos uma perspectiva não-essencialista das identidades; por isso, consideramos que as identidades são sempre múltiplas e se constituem social e culturalmente.

\section{Referências}

ARFUCH, Leonor. Identidades, sujetos y subjetividades. Buenos Aires: Prometeo Libros, 2002.

BAUMAN, Zigmunt. Identidade. Rio de Janeiro: Editora Jorge Zahar, 2005.

Comunidade. Rio de Janeiro: Editora Jorge $\overline{\text { Zahar, }} 2003$.

CORRÊA, Anderson Rodrigues. No escurinho do 
cinema... Sobre HIV-AIDS, gênero e sexualidade em filmes hollywoodianos. 2007. Dissertação (Mestrado em Educação) Programa de Pós-graduação em Educação da Universidade Federal do Rio Grande do Sul. UFRG, Rio Grande do Sul - RS.

COSTA, Marisa Vorraber. Estudos Culturais e Educação - um panorama. In: SILVEIRA, Rosa Maria Hessel (Org.). Cultura, Poder e Educação. Um debate sobre Estudos Culturais em Educação. Canoas: Editora Ulbra, 2005. p. 107-120.

Estudos Culturais em Educação: mídia, arquitetura, brinquedo, biologia, literatura, cinema... Porto Alegre: Editora Universidade UFRGS, 2000.

FANTIN, Mônica. Cinema e Imaginário Infantil: a Mediação entre o Visível e o Invisível. Educação \& Realidade: Porto Alegre, v. 34 n. 2. p.205-223 mai. ago. 2009.

FREITAS, Letícia Fonseca Richthofen. A pedagogia do gauchismo: uma análise a partir da diáspora gaúcha. 2006. Tese (Doutorado em Educação) Programa de Pós-graduação em Educação da Universidade Federal do Rio Grande do Sul. Rio Grande do Sul - RS.

HAESBAERT, Rogério. Identidades territoriais. In: ROSENDAHL, Zeny; CORREAA, Roberto Lobato (Org.). Manifestações da cultura no espaço. Rio de Janeiro: Editora UERJ, 1999. p. 169-190.

Des-territorialização e identidade. A rede "gaúcha" no Nordeste. Niterói: EDUFF, 1997.

HALL, Stuart. Da Diáspora. Belo Horizonte: Editora UFMG, 2003a.

. A Identidade cultural na pós-modernidade. 8 ed. Rio de Janeiro: DP\&A, 2003 b.

LOURO, Guacira Lopes. Gênero, sexualidade e educação. 4 ed. Petrópolis, Rio de Janeiro: Vozes, 2001.

MEYER, Dagmar. Escola, currículo e produção de diferenças e desigualdades de gênero. In: SCHOLZE, Lia (Org.) Gênero, memória e docência. Porto Alegre: Prefeitura Municipal de Porto Alegre, Secretaria Municipal de Educação, 2001. p. s/p.

MOREIRA, Antônio Flávio. Currículo e Estudos
Culturais: tensões e desafios em torno das identidades. In: SILVEIRA, Rosa Maria Hessel (Org.). Cultura, Poder e Educação. Um debate sobre Estudos Culturais em Educação. Canoas: Editora Ulbra, 2005. p. 123-143

SILVEIRA, Rosa Maria Hessel. A Língua não nos separa. In: A Educação na Cultura da Mídia e do Consumo. COSTA, Marisa Vorraber (Org.). Rio de Janeiro: Lamparina, 2009. p. s/p.

Filme:

CANTET, Laurent. Entre os muros da escola (Entre les murs). França, 2008. 